\title{
Performance of the CKD-EPI creatinine-cystatin C glomerular filtration rate estimation equations in a multiethnic Asian population
}

Boon Wee $\underline{T e O}^{1}$, MB, BCh, Yun Yin $\underline{K o h}^{2}$, BS, Qi Chun $\underline{T o h}{ }^{1}$, BSc, Jialiang $\underline{L} \underline{i}^{2}$, PhD, Arvind Kumar $\underline{\operatorname{Sinha}}^{3}$, MD, Borys Shuter ${ }^{4}$, PhD, Sunil Sethi ${ }^{5}$, PhD, Evan JC $\underline{\text { Lee }}^{1}$, MD

INTRODUCTION Clinical practice guidelines recommend using creatinine-based equations to estimate glomerular filtration rates (GFRs). While these equations were formulated for Caucasian-American populations and have adjustment coefficients for African-American populations, they are not validated for other ethnicities. The Chronic Kidney Disease-Epidemiology Collaborative Group (CKD-EPI) recently developed a new equation that uses both creatinine and cystatin C. We aimed to assess the accuracy of this equation in estimating the GFRs of participants (healthy and with chronic kidney disease [CKD]) from a multiethnic Asian population.

METHODS Serum samples from the Asian Kidney Disease Study and the Singapore Kidney Function Study were used. GFR was measured using plasma clearance of ${ }^{99 \mathrm{~m} T C}$-DTPA. GFR was estimated using the CKD-EPI equations. The performance of GFR estimation equations were examined using median and interquartile range values, and the percentage difference from the measured GFR.

RESULTS The study comprised 335 participants $(69.3 \%$ with CKD; $38.5 \%$ Chinese, 29.6\% Malays, $23.6 \%$ Indians, $8.3 \%$ others), with a mean age of $53.5 \pm 15.1$ years. Mean standardised serum creatinine was $127 \pm 86 \mu \mathrm{mol} / \mathrm{L}$, while mean standardised serum cystatin $\mathrm{C}$ and mean measured GFR were $1.43 \pm 0.74 \mathrm{mg} / \mathrm{L}$ and $67 \pm 33 \mathrm{~mL} / \mathrm{min} / 1.73 \mathrm{~m}^{2}$, respectively. The creatinine-cystatin C CKD-EPI equation performed the best, with an estimated GFR of $67 \pm 35 \mathrm{~mL} / \mathrm{min} / 1.73 \mathrm{~m}^{2}$.

CONCLUSION The new creatinine-cystatin C equation estimated GFR with little bias, and had increased precision and accuracy in our multiethnic Asian population. This two-biomarker equation may increase the accuracy of population studies on CKD, without the need to consider ethnicity.

Keywords: Asian, chronic kidney disease, creatinine, cystatin C, glomerular filtration rate

\section{INTRODUCTION}

The use of coefficients to adjust for ethnicity in equations estimating glomerular filtration rate (GFR) is impractical. ${ }^{(1,2)}$ Although coefficients for ethnicities other than 'white' or 'black' have been derived for the Modification of Diet in Renal Disease (MDRD) equation, these coefficients do not necessarily yield accurate estimations. ${ }^{(1,3)}$ The combined use of serum creatinine and cystatin $C$ biomarkers in equations estimating GFR has been shown to improve the accuracy of GFR estimation and reduce the effect of ethnicity as a predictor. ${ }^{(4)}$ In fact, a recent study showed that the effect ethnicity had on GFR estimation was rendered insignificant when beta-trace protein (BTP), creatinine and cystatin $\mathrm{C}$ were used in the equation. ${ }^{(5)}$

The equation developed by the Chronic Kidney DiseaseEpidemiology Collaborative Group (CKD-EPI) is preferred when estimating GFRs in multiethnic populations because of its reduced bias. CKD-EPI has also developed a new equation that incorporates both serum creatinine and cystatin C, using a population comprising both healthy individuals and chronic kidney disease (CKD) patients. ${ }^{(2)}$ We assessed the performance of the new creatinine-cystatin C CKD-EPI equation in a study cohort consisting of healthy participants and patients with CKD who have undergone radionuclide GFR measurement.

\section{METHODS}

The present study, which was approved by the institution review board, utilised the serum samples of research participants $(\mathrm{n}=335)$ from the Asian Kidney Disease Study and Singapore Kidney Function Study. ${ }^{(3,6)}$ The stored serum samples were assayed for cystatin C. In the Asian Kidney Disease Study, patients with stable CKD from the outpatient renal clinics of National University Hospital, Singapore, were recruited $(n=232) .^{(3)}$ In the Singapore Kidney Function Study, healthy participants who had normal kidney function and who reported having no diagnosis of hypertension or diabetes mellitus were recruited $(n=103){ }^{(6)}$ All participants from both studies underwent urine dipstick tests to exclude microalbuminuria, leucocyturia and erythrocyturia. Participants were recruited consecutively using stratified sampling; they were stratified according to the four ethnic groups (Chinese, Malay, Indian and others) and then by gender. In both studies, participants performed self-directed 24-hour urine collections and underwent GFR measurements the next day, during which blood and spot urine samples were also collected. 
Participants were allowed a light, no-protein breakfast before GFR determination, according to the British Nuclear Medicine Society guidelines. GFR determination was done using three-sample plasma clearance of ${ }^{99 m}$ technetium-diethylene triamine pentaacetic acid ( ${ }^{99 m}$ Tc-DTPA), via an intravenous injection of TechneScan DTPA (Mallinckrodt Medical BV, Le Petten, Netherlands). ${ }^{(7)}$ GFR was calculated using the slope-intercept method, normalised to body surface area using the du Bois equation, and corrected using the Brochner-Mortensen equation..$^{(8,9)}$ Serum creatinine was calibrated with materials traceable to standardised creatinine and measured using an enzymatic (creatinase) method (www.siemens. com). ${ }^{(3)}$ Serum cystatin C were measured using particle-enhanced immunonephelometry on the BN Prospec platform (Siemens, Munich, Bavaria, Germany). All assays were performed in a central clinical laboratory accredited by the College of American Pathologists. Some studies have reported a drift in serum cystatin C using the Siemens assay. ${ }^{(10-12)}$ As there is a standard cystatin $C$ calibration material (ERM-DA471/IFCC), we calculated standardised serum cystatin $\mathrm{C}(\mathrm{Scys} \mathrm{C})$ using the adjustment equation 2 from the study by Inker et al: ScysC $=1.12 \times$ cysC. $^{(12)}$

Estimated GFR (eGFR) was calculated based on the CKDEPI equations using (a) creatinine only; (b) cystatin $\mathrm{C}$ only; and (c) creatinine and cystatin C combined. ${ }^{(2)}$ We assessed the performance of the estimation equations using performance metrics similar to that used by Inker et al. ${ }^{(2)}$ Bias was defined as the difference between the median of the measured GFR and the median of the eGFR, while precision was defined as the interquartile range (IQR) of that difference. Accuracy was assessed based on the percentage of eGFRs that differed by more than $30 \%$ (1-P30) or 20\% (1-P20) from the measured GFRs. Confidence intervals were calculated using a bootstrap method (2,000 bootstraps). Using the creatinine-only CKD-EPI equation as the comparator, the significance of the differences between the creatinine-only CKD-EPI equation and other equations were determined using signed-rank test for bias. To compare the interquartile ranges from the 2,000 bootstrap samples, $t$-test was used, while McNemar's test was used to compare the 1-P30 and 1-P20.

\section{RESULTS}

Our study population ( $\mathrm{n}=335$ ) had 171 male participants (51.0\%). Of the 335 participants, 129 (38.5\%) were Chinese, 99 (29.6\%) were Malay, 79 (23.6\%) were Indian and 28 (8.4\%) were of other ethnicities (Table I). The mean basic characteristics of the participants are as follows: (a) age $-53.5 \pm 15.1$ years;

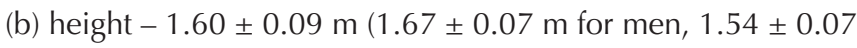
for women); (c) weight $-68.9 \pm 15.1 \mathrm{~kg}(74.8 \pm 14.1 \mathrm{~kg}$ for men, $62.8 \pm 13.8$ for women); (d) body mass index $-26.8 \pm$ $5.2 \mathrm{~kg} / \mathrm{m}^{2}$; and (e) body surface area $-1.72 \pm 0.2 \mathrm{~m}^{2}$. The mean laboratory measurements of the participants are as follows: (a) GFR - $67 \pm 33 \mathrm{~mL} / \mathrm{min} / 1.73 \mathrm{~m}^{2}\left(101 \pm 16 \mathrm{~mL} / \mathrm{min} / 1.73 \mathrm{~m}^{2}\right.$ for healthy participants, $52 \pm 27 \mathrm{~mL} / \mathrm{min} / 1.73 \mathrm{~m}^{2}$ for patients with CKD); (b) standardised serum creatinine $-127 \pm 86 \mu \mathrm{mol} / \mathrm{L}$ $(149 \pm 93 \mu \mathrm{mol} / \mathrm{L}$ for men, $104 \pm 72 \mu \mathrm{mol} / \mathrm{L}$ for women); and (c) standardised serum cystatin C $-1.43 \pm 0.74 \mathrm{mg} / \mathrm{L}$. The median eGFR of the CKD-EPI equations are as follows: (a) creatinine-only
Table I. Demographics, laboratory measurements and estimated glomerular filtration rates (eGFRs) of the study's participants (n = 335).

\begin{tabular}{|c|c|}
\hline Parameter & Mean \pm SD \\
\hline Age (yrs) & $53.5 \pm 15.1$ \\
\hline \multicolumn{2}{|l|}{ Gender* } \\
\hline Male & $171(51.0)$ \\
\hline Female & $164(49.0)$ \\
\hline \multicolumn{2}{|l|}{ Ethnicity* } \\
\hline Chinese & $129(38.5)$ \\
\hline Malay & $99(29.6)$ \\
\hline Indian & $79(23.6)$ \\
\hline Others & $28(8.4)$ \\
\hline Chronic kidney disease* & $232(69.3)$ \\
\hline With diabetes mellitus & $119(35.5)$ \\
\hline With hypertension & $192(57.3)$ \\
\hline With diabetes mellitus and hypertension & $109(32.5)$ \\
\hline Height (m) & $1.60 \pm 0.09$ \\
\hline Weight (kg) & $68.9 \pm 15.1$ \\
\hline Body mass index $\left(\mathrm{kg} / \mathrm{m}^{2}\right)$ & $26.8 \pm 5.21$ \\
\hline Body surface area $\left(\mathrm{m}^{2}\right)$ & $1.72 \pm 0.21$ \\
\hline Serum creatinine ( $\mu \mathrm{mol} / \mathrm{L})$ & $127 \pm 86$ \\
\hline Serum cystatin C (mg/L) & $1.43 \pm 0.74$ \\
\hline Measured GFR $\left(\mathrm{mL} / \mathrm{min} / 1.73 \mathrm{~m}^{2}\right)$ & $67 \pm 33$ \\
\hline Creatinine-only eGFR ${ }^{+}\left(\mathrm{mL} / \mathrm{min} / 1.73 \mathrm{~m}^{2}\right)$ & $69 \pm 36$ \\
\hline Cystatin C-only eGFR ${ }^{+}\left(\mathrm{mL} / \mathrm{min} / 1.73 \mathrm{~m}^{2}\right)$ & $65 \pm 33$ \\
\hline $\begin{array}{l}\text { Average of creatinine-cystatin C eGFR }{ }^{+} \\
\left(\mathrm{mL} / \mathrm{min} / 1.73 \mathrm{~m}^{2}\right)\end{array}$ & $67 \pm 34$ \\
\hline Creatinine-cystatin C eGFR ${ }^{+}\left(\mathrm{mL} / \mathrm{min} / 1.73 \mathrm{~m}^{2}\right)$ & $67 \pm 35$ \\
\hline
\end{tabular}

*Data is presented as number (percentage). teGFR calculated using the CKD-EPI equations by Inker et al. ${ }^{(2)}$ SD: standard deviation

equation - $72\left(\mathrm{IQR}\right.$ 63.9) $\mathrm{mL} / \mathrm{min} / 1.73 \mathrm{~m}^{2}$; (b) cystatin C-only equation - 64 (IQR 58.5) $\mathrm{mL} / \mathrm{min} / 1.73 \mathrm{~m}^{2}$; (c) average of creatinine and cystatin C estimates - 67 (IQR 60.3) mL/min/1.73 $\mathrm{m}^{2}$; and (d) creatinine and cystatin $\mathrm{C}$ combination (i.e. creatininecystatin C) equation - 67 (IQR: 62.4) $\mathrm{mL} / \mathrm{min} / 1.73 \mathrm{~m}^{2}$. These estimates were similar to measured GFR $(p=0.47, p=0.53$, $p=0.96$ and $p=1.0$, respectively)

Overall, the creatinine-only equation performed with little bias (Table II). Its bias was greatest when predicting GFR $\geq 90 \mathrm{~mL} / \mathrm{min} / 1.73 \mathrm{~m}^{2}$, whereas the cystatin C-only equation had the highest bias in the $60-89 \mathrm{~mL} / \mathrm{min} / 1.73 \mathrm{~m}^{2}$ category. Similarly, estimation performance was inconsistent across the GFR categories. When compared to the creatinine-only equation, the creatininecystatin $\mathrm{C}$ equation appeared to result in marginal improvement in precision; however, the latter had worse precision in the GFR $\geq 90 \mathrm{~mL} / \mathrm{min} / 1.73 \mathrm{~m}^{2}$ category. Overall, the 1-P30 and 1-P20 accuracy improved by about $4 \%-6 \%$ using the creatinine-cystatin C equation, but this was similarly inconsistent across GFR categories.

\section{DISCUSSION}

The present study is the first to assess the accuracy of the CKD-EPI GFR estimation equations in a multiethnic Asian population comprising both healthy participants and CKD patients. We found that while the CKD-EPI creatinine-only equation estimated GFR well, it was more biased at normal GFR levels 
Table II. Performance of the Chronic Kidney Disease-Epidemiology Collaborative Group (CKD-EPI) glomerular filtration rate (GFR) estimation equations in a multiethnic Asian population made up of healthy individuals and chronic kidney disease patients $(n=335)$.

\begin{tabular}{|c|c|c|c|c|c|c|c|c|}
\hline \multirow[t]{2}{*}{ Parameter } & \multicolumn{8}{|c|}{ Estimated GFR } \\
\hline & Overall & p-value* & $\begin{array}{c}<60 \mathrm{~mL} / \mathrm{min} / \\
1.73 \mathrm{~m}^{2}\end{array}$ & p-value* & $\begin{array}{c}60-89 \mathrm{~mL} / \mathrm{min} / \\
1.73 \mathrm{~m}^{2}\end{array}$ & p-value* & $\begin{array}{c}\geq 90 \mathrm{~mL} / \mathrm{min} / \\
1.73 \mathrm{~m}^{2}\end{array}$ & p-value* \\
\hline \multicolumn{9}{|l|}{ Bias $^{+}$} \\
\hline Creatinine equation & $\begin{array}{c}-0.036 \\
(-1.23,1.58)\end{array}$ & - & $\begin{array}{c}-2.74 \\
(-4.31,-1.80)\end{array}$ & - & $\begin{array}{c}2.12 \\
(-2.83,7.94)\end{array}$ & - & $\begin{array}{c}6.32 \\
(4.18,9.70)\end{array}$ & - \\
\hline Cystatin $\mathrm{C}$ equation & $\begin{array}{c}-2.93 \\
(-3.82,-1.20)\end{array}$ & $<0.001$ & $\begin{array}{c}-3.33 \\
(-4.15,-1.43)\end{array}$ & $<0.001$ & $\begin{array}{c}-7.57 \\
(-14.33,-4.89)\end{array}$ & $<0.001$ & $\begin{array}{c}2.45 \\
(-1.40,7.57)\end{array}$ & $<0.001$ \\
\hline $\begin{array}{l}\text { Creatinine-cystatin C } \\
\text { equation }\end{array}$ & $\begin{array}{c}-1.21 \\
(-2.77,-0.16)\end{array}$ & $<0.001$ & $\begin{array}{c}-2.80 \\
(-4.51,-1.27)\end{array}$ & $<0.001$ & $\begin{array}{c}-1.84 \\
(-6.66,2.26)\end{array}$ & $<0.001$ & $\begin{array}{c}3.30 \\
(0.23,8.23)\end{array}$ & $<0.001$ \\
\hline $\begin{array}{l}\text { Average of creatinine } \\
\text { and cystatin C }\end{array}$ & $\begin{array}{c}-1.17 \\
(-2.12,0.11)\end{array}$ & $<0.001$ & $\begin{array}{c}-1.99 \\
(-3.53,-0.38)\end{array}$ & $<0.001$ & $\begin{array}{c}0.04 \\
(-5.32,3.15)\end{array}$ & $<0.001$ & $\begin{array}{c}2.11 \\
(-1.27,5.75)\end{array}$ & $<0.001$ \\
\hline \multicolumn{9}{|l|}{ Precision ${ }^{*}$} \\
\hline Creatinine equation & $\begin{array}{c}15.37 \\
(13.26,17.69)\end{array}$ & - & $\begin{array}{c}9.74 \\
(6.97,11.65)\end{array}$ & - & $\begin{array}{c}19.57 \\
(14.18,29.08)\end{array}$ & - & $\begin{array}{c}16.85 \\
(13.53,21.07)\end{array}$ & - \\
\hline Cystatin $\mathrm{C}$ equation & $\begin{array}{c}14.03 \\
(12.23,16.83)\end{array}$ & $<0.001$ & $\begin{array}{c}9.37 \\
(7.20,10.58)\end{array}$ & $<0.001$ & $\begin{array}{c}22.38 \\
(14.47,26.73)\end{array}$ & $<0.001$ & $\begin{array}{c}22.54 \\
(17.13,27.84)\end{array}$ & $<0.001$ \\
\hline $\begin{array}{l}\text { Creatinine-cystatin C } \\
\text { equation }\end{array}$ & $\begin{array}{c}13.74 \\
(11.30,15.92)\end{array}$ & $<0.001$ & $\begin{array}{c}8.01 \\
(6.08,9.44)\end{array}$ & $<0.001$ & $\begin{array}{c}16.27 \\
(11.71,20.76)\end{array}$ & $<0.001$ & $\begin{array}{c}21.03 \\
(16.98,25.70)\end{array}$ & $<0.001$ \\
\hline $\begin{array}{l}\text { Average of creatinine } \\
\text { and cystatin C }\end{array}$ & $\begin{array}{c}13.70 \\
(10.82,15.31)\end{array}$ & $<0.001$ & $\begin{array}{c}7.77 \\
(5.97,9.35)\end{array}$ & $<0.001$ & $\begin{array}{c}14.76 \\
(11.64,19.71)\end{array}$ & $<0.001$ & $\begin{array}{c}20.40 \\
(17.51,24.71)\end{array}$ & $<0.001$ \\
\hline \multicolumn{9}{|l|}{ Accuracy wrt 1-P30\$ } \\
\hline Creatinine equation & $\begin{array}{c}13.73 \\
(10.05,17.42)\end{array}$ & - & $\begin{array}{c}14.47 \\
(8.89,20.07)\end{array}$ & - & $\begin{array}{c}22.87 \\
(11.91,33.70)\end{array}$ & - & $\begin{array}{c}8.73 \\
(3.80,13.66)\end{array}$ & - \\
\hline Cystatin $\mathrm{C}$ equation & $\begin{array}{c}12.84 \\
(9.25,16.42)\end{array}$ & 0.73 & $\begin{array}{c}16.15 \\
(10.46,21.83)\end{array}$ & 0.68 & $\begin{array}{c}8.57 \\
(2.01,15.13)\end{array}$ & 0.025 & $\begin{array}{c}10.58 \\
(4.67,16.49)\end{array}$ & 0.63 \\
\hline $\begin{array}{l}\text { Creatinine-cystatin C } \\
\text { equation }\end{array}$ & $\begin{array}{c}9.85 \\
(6.66,13.04)\end{array}$ & 0.11 & $\begin{array}{c}9.03 \\
(4.52,13.54)\end{array}$ & 0.13 & $\begin{array}{c}12.5 \\
(4.40,20.60)\end{array}$ & 0.13 & $\begin{array}{c}9.48 \\
(4.15,14.81)\end{array}$ & 0.83 \\
\hline $\begin{array}{l}\text { Average of creatinine } \\
\text { and cystatin } C\end{array}$ & $\begin{array}{c}8.96 \\
(5.90,12.01)\end{array}$ & 0.051 & $\begin{array}{c}10.60 \\
(5.69,15.51)\end{array}$ & 0.30 & $\begin{array}{c}10.45 \\
(3.12,17.78)\end{array}$ & 0.06 & $\begin{array}{c}5.98 \\
(1.69,10.28)\end{array}$ & 0.41 \\
\hline \multicolumn{9}{|l|}{ Accuracy wrt 1-P20\$ } \\
\hline Creatinine equation & $\begin{array}{c}28.96 \\
(24.10,33.81)\end{array}$ & - & $\begin{array}{c}35.53 \\
(27.91,43.13)\end{array}$ & - & $\begin{array}{c}35.09 \\
(22.70,47.48)\end{array}$ & - & $\begin{array}{c}18.25 \\
(11.51,24.99)\end{array}$ & - \\
\hline Cystatin $\mathrm{C}$ equation & $\begin{array}{c}29.55 \\
(24.57,34.44)\end{array}$ & 0.86 & $\begin{array}{c}34.16 \\
(26.84,41.49)\end{array}$ & 0.80 & $\begin{array}{c}28.57 \\
(17.99,39.15)\end{array}$ & 0.43 & $\begin{array}{c}23.07 \\
(14.97,31.12)\end{array}$ & 0.36 \\
\hline $\begin{array}{l}\text { Creatinine-cystatin C } \\
\text { equation }\end{array}$ & $\begin{array}{c}25.37 \\
(20.71,30.03)\end{array}$ & 0.29 & $\begin{array}{c}31.61 \\
(24.29,38.93)\end{array}$ & 0.46 & $\begin{array}{c}23.44 \\
(13.06,33.82)\end{array}$ & 0.15 & $\begin{array}{c}18.10 \\
(11.10,25.11)\end{array}$ & 0.97 \\
\hline $\begin{array}{l}\text { Average of creatinine } \\
\text { and cystatin C }\end{array}$ & $\begin{array}{c}22.99 \\
(18.48,27.49)\end{array}$ & 0.078 & $\begin{array}{c}28.48 \\
(21.28,35.68)\end{array}$ & 0.18 & $\begin{array}{c}22.39 \\
(12.41,32.37)\end{array}$ & 0.11 & $\begin{array}{c}16.24 \\
(9.56,22.92)\end{array}$ & 0.67 \\
\hline
\end{tabular}

*Compared to the CKD-EPI creatinine-only equation. ${ }^{*}$ Data is presented as median difference $(95 \% \mathrm{Cl})$. ${ }^{\star}$ Data is presented as IQR of the difference $(95 \% \mathrm{CI})$. ${ }^{5} \mathrm{Data}$ is presented as percentage $(95 \% \mathrm{Cl})$. $\mathrm{Cl}$ : confidence interval; IQR: interquartile range; wrt: with respect to

$\left(\geq 90 \mathrm{~mL} / \mathrm{min} / 1.73 \mathrm{~m}^{2}\right)$. Conversely, the CKD-EPI cystatin C equation estimated GFR with more bias and less accuracy at lower GFRs $\left(<60 \mathrm{~mL} / \mathrm{min} / 1.73 \mathrm{~m}^{2}\right)$. In general, if creatinine-only equations are used for estimating GFR, there is a concern that the 'creatinine-blind' range of $60-89 \mathrm{~mL} / \mathrm{min} / 1.73 \mathrm{~m}^{2}$ may result in incorrect estimations, which may in turn cause participants in general population studies to be inaccurately classified as CKD patients (defined by GFR < 60). ${ }^{(13-15)}$ Using both biomarkers (i.e. creatinine and cystatin C) together for estimation appears to improve precision and accuracy in the $60-89 \mathrm{~mL} / \mathrm{min} / 1.73 \mathrm{~m}^{2}$ GFR range. Overall, estimation equations that use both biomarkers perform better than equations that use only one biomarker. The performance of the creatinine-cystatin $C$ equation used in our study is similar or better than that reported in external population datasets that were used to validate the equation. ${ }^{(2)}$

One criticism of the MDRD GFR estimation equation is that its derivation was done using data from CKD patients only. As a consequence, the equation only has the ability to report for GFR $<60 \mathrm{~mL} / \mathrm{min} / 1.73 \mathrm{~m}^{2}$. There is also the concern that CKD staging misclassification may occur for patients with GFRs in the range of $50-70 \mathrm{~mL} / \mathrm{min} / 1.73 \mathrm{~m}^{2}$. Furthermore, the discrepant findings of Chinese and Japanese investigators regarding the magnitude and direction of ethnic coefficients for the MDRD equation have caused much difficulty in determining a valid method for estimating GFRs in Asians and other non-American multiethnic populations. ${ }^{(16,17)}$ Therefore, the CKD-EPI equation appears to be superior to the MDRD equation. ${ }^{(4,18)}$ The two-biomarker CKDEPI equation proposed by Inker et al may eliminate the need to factor in ethnicity during GFR estimations, as well as increase the accuracy of population studies on CKD. ${ }^{(2)}$

The proliferation of proposed ethnicity coefficients for adjusting the MDRD and CKD-EPI equations is alarming, as study designs may not have permitted such conclusions to be drawn. ${ }^{16,19)}$ The results of the present study suggest that the 
new creatinine-cystatin C CKD-EPI equation is able to produce eGFRs with reasonable accuracy over a broader range of GFRs, in patients with and without CKD. It is unlikely that there will be a perfectly accurate GFR estimation equation for all clinical scenarios. We recommend, when cost permits, the use of the two-biomarker GFR estimation equation without any adjustment for ethnicity, especially in epidemiological studies. This equation is also useful in multiethnic populations (e.g. global cities), in subpopulations where ethnicity is unclear (e.g. persons born of multiple ethnicities) and among patients with extreme body size.

We are of the opinion that it is not imperative to know exactly or accurately what the 'true' GFR is. Instead, it is more important that a fairly accurate and consistent estimation is performed for any given biomarker or combination of biomarkers. This is because consistency allows for comparisons between different groups internationally. On this basis, we suggest that CKD-EPI equations be used for estimations of GFR in clinical practice and research, and that the use of the creatinine-cystatin C CKD-EPI equation (or the average of the creatinine-only equation and the cystatin C-only equation) be strongly considered when cost is not a barrier. ${ }^{(2,4,5)}$

In conclusion, the new creatinine-cystatin C CKD-EPI equation was able to estimate GFR with little bias, and with increased precision and accuracy in a multiethnic Asian population. This suggests that the use of a two-biomarker CKD-EPI GFR estimation equation, without any adjustment for ethnicity, may reduce misclassification of CKD in epidemiological studies.

\section{ACKNOWLEDGEMENTS}

This study was funded by the Ministry of Education Academic Research Fund, which was awarded to Dr Teo by the Faculty Research Committee of the Yong Loo Lin School of Medicine, National University of Singapore, Singapore, for the project 'Multiple-biomarker approach to glomerular filtration rate determination in healthy and chronic kidney disease patients'. The Asian Kidney Disease Study and Singapore Kidney Function Study were funded by the National Medical Research Council (block vote) and the National Kidney Foundation of Singapore (NKFRC2007/08). We acknowledge Dr Xu Hui for her help in recruiting the research participants.

\section{REFERENCES}

1. Rule AD, Teo BW. GFR estimation in Japan and China: what accounts for the difference? Am J Kidney Dis 2009; 53:932-5.

2. Inker LA, Schmid $\mathrm{CH}$, Tighiouart $\mathrm{H}$, et al. Estimating glomerular filtration rate from serum creatinine and cystatin C. N Engl J Med 2012; 367:20-9.

3. Teo BW, $\mathrm{Xu} \mathrm{H}$, Wang D, et al. GFR estimating equations in a multiethnic Asian population. Am J Kidney Dis 2011; 58:56-63.

4. Teo BW, Xu H, Wang D, et al. Estimating glomerular filtration rates by use of both cystatin $\mathrm{C}$ and standardized serum creatinine avoids ethnicity coefficients in Asian patients with chronic kidney disease. Clin Chem 2012; 58:450-7.

5. Teo BW, Xu H, Koh YY, et al. Estimating kidney function in a multiethnic Asian population with multiple filtration markers. Am J Kidney Dis 2012; 60:500-2.

6. Teo BW, Xu H, Koh YY, et al. Glomerular filtration rates in healthy Asians without kidney disease. Nephrology (Carlton) 2014; 19:72-9.

7. Fleming JS, Zivanovic MA, Blake GM, Burniston M, Cosgriff PS. Guidelines for the measurement of glomerular filtration rate using plasma sampling. Nucl Med Commun 2004; 25:759-69.

8. Bröchner-Mortensen J. A simple method for the determination of glomerular filtration rate. Scand J Clin Lab Invest 1972; 30:271-4.

9. Du Bois D, Du Bois EF. A formula to estimate the approximate surface area if height and weight be known. 1916. Nutrition 1989; 5:303-11.

10. Larsson A, Hansson LO, Flodin M, Katz R, Shlipak MG. Calibration of the Siemens cystatin $\mathrm{C}$ immunoassay has changed over time. Clin Chem 2011; 57:777-8.

11. Voskoboev NV, Larson TS, Rule AD, Lieske JC. Importance of cystatin C assay standardization. Clin Chem 2011; 57:1209-11.

12. Inker LA, Eckfeldt J, Levey AS, et al. Expressing the CKD-EPI (Chronic Kidney Disease Epidemiology Collaboration) cystatin $C$ equations for estimating GFR with standardized serum cystatin C values. Am J Kidney Dis 2011; 58:682-4.

13. Herget-Rosenthal S, Bökenkamp A, Hofmann W. How to estimate GFRserum creatinine, serum cystatin C or equations? Clin Biochem 2007; 40:153-61.

14. Rule AD, Larson TS, Bergstralh EJ, et al. Using serum creatinine to estimate glomerular filtration rate: accuracy in good health and in chronic kidney disease. Ann Intern Med 2004; 141:929-37.

15. Zuo L, Ma YC, Zhou YH, et al. Application of GFR-estimating equations in Chinese patients with chronic kidney disease. Am J Kidney Dis 2005; 45:463-72.

16. Ma YC, Zuo L, Chen JH, et al. Modified glomerular filtration rate estimating equation for Chinese patients with chronic kidney disease. J Am Soc Nephrol 2006; 17:2937-44

17. Matsuo S, Imai E, Horio M, et al. Revised equations for estimated GFR from serum creatinine in Japan. Am J Kidney Dis 2009; 53:982-92.

18. Teo BW, Ng ZY, Li J, et al. The choice of estimating equations for glomerular filtration rate significantly affects the prevalence of chronic kidney disease in a multi-ethnic population during health screening. Nephrology (Carlton) 2009; 14:588-96.

19. Praditpornsilpa K, Townamchai N, Chaiwatanarat $T$, et al. The need for robust validation for MDRD-based glomerular filtration rate estimation in various CKD populations. Nephrol Dial Transplant 2011; 26:2780-5. 